Nat. Hazards Earth Syst. Sci., 18, 2455-2469, 2018

https://doi.org/10.5194/nhess-18-2455-2018

(C) Author(s) 2018. This work is distributed under

the Creative Commons Attribution 4.0 License.

\title{
Effective surveyed area and its role in statistical landslide susceptibility assessments
}

\author{
Txomin Bornaetxea ${ }^{1}$, Mauro Rossi ${ }^{2}$, Ivan Marchesini ${ }^{2}$, and Massimiliano Alvioli ${ }^{2}$ \\ ${ }^{1}$ Department of Geography, Prehistory and Archaeology, Faculty of Arts of the University of the Basque Country UPV/EHU, \\ c/ Tomás y Valiente, s/n, 01006, Vitoria-Gasteiz, Spain \\ ${ }^{2}$ Consiglio Nazionale delle Ricerche, Istituto di Ricerca per la Protezione Idrogeologica, via Madonna Alta 126, \\ 06128 Perugia, Italy
}

Correspondence: Txomin Bornaetxea (txomin.bornaetxea@ehu.eus)

Received: 28 March 2018 - Discussion started: 9 April 2018

Revised: 13 July 2018 - Accepted: 21 August 2018 - Published: 14 September 2018

\begin{abstract}
Geomorphological field mapping is a conventional method used to prepare landslide inventories. The approach is typically hampered by the accessibility and visibility, during field campaigns for landslide mapping, of the different portions of the study area. Statistical significance of landslide susceptibility maps can be significantly reduced if the classification algorithm is trained in unsurveyed regions of the study area, for which landslide absence is typically assumed, while ignorance about landslide presence should actually be acknowledged. We compare different landslide susceptibility zonations obtained by training the classification model either in the entire study area or in the only portion of the area that was actually surveyed, which we name effective surveyed area. The latter was delineated by an automatic procedure specifically devised for the purpose, which uses information gathered during surveys, along with landslide locations. The method was tested in Gipuzkoa Province (Basque Country), north of the Iberian Peninsula, where digital thematic maps were available and a landslide survey was performed. We prepared the landslide susceptibility maps and the associated uncertainty within a logistic regression model, using both slope units and regular grid cells as the reference mapping unit. Results indicate that the use of effective surveyed area for landslide susceptibility zonation is a valid approach that minimises the limitations stemming from unsurveyed regions at landslide mapping time. Use of slope units as mapping units, instead of grid cells, mitigates the uncertainties introduced by training the automatic classifier within the entire study area. Our method pertains to data preparation and, as such, the relevance of our conclusions is not limited
\end{abstract}

to the logistic regression but are valid for virtually all the existing multivariate landslide susceptibility models.

\section{Introduction}

Landslide susceptibility is defined as the likelihood of a landslide occurring in an area on the basis of the local terrain and environmental conditions (Brabb, 1984; Guzzetti et al., 2005). Landslide susceptibility zonation (LSZ) is important for landslide mitigation plans, since it supplies planners and decision makers with essential information (Van Den Eeckhaut et al., 2012). A large number of LSZ studies based on statistical methodologies (Reichenbach et al., 2018) and comparative studies (Cascini, 2008; Das et al., 2010; Schicker, 2010; Amorim, 2012; Blais-Stevens et al., 2012; Trigila et al., 2015; Wang et al., 2015) were published in the last decades. Many statistical methods, aimed at estimating the propensity of a territory to experience slope failures, rely on landslide inventory maps and spatial thematic layers as predisposing factors (Ermini et al., 2005; Van Den Eeckhaut et al., 2006; Camilo et al., 2017).

In statistical landslide susceptibility models, such as the logistic regression (LR) model adopted in this work, the preparation of the training data set is a fundamental and critical step. Commonly, this requires the selection of a sample of stable (without landslides) and unstable (with landslides) mapping units. While ensuring the presence of a landslide is straightforward and can be supported by the geomorphological signatures on the slope or by direct observation of 
the events, the selection of landslide-free areas is more critical. Assuming as landslide-free the locations of a study area where no landslides were reported in a field survey is correct only in the unlikely circumstance that the landslide inventory has been prepared by surveying every single site of the study area and following homogeneous criteria. In other words, any landslide-free location in an inventory map should have been explicitly checked to be free from landslides.

Nowadays, there are methods based on the visual interpretation of aerial photographs or digital processing of remotely acquired optical and radar imagery (Catani et al., 2005; Herrera et al., 2009; Fiorucci et al., 2011, 2018; Casagli et al., 2017; Mondini, 2017; Alvioli et al., 2018b), which allow historical and event landslide inventories to be prepared. However, the adoption of such methods can be hampered by the lack of imagery or image interpretation expertise, low performance of automatic classification and other factors. Alternatively, bibliographic sources like newspapers and news feeds, administrative reports or scientific literature can be used for obtaining landslide information. Nevertheless, the downside of these type of data is that they are rarely as accurate as required by LSZ studies. As a consequence, sometimes the best option for obtaining a reliable landslide inventory is a straightforward geomorphological field mapping. A detailed discussion about the characteristics, advantages and limitations of different approaches for landslide mapping can be found in Guzzetti et al. (2012) Santangelo et al. (2015) and Fiorucci et al. (2018).

An operational disadvantage of field-based landslide mapping is the difficulty in surveying the whole area where the LSZ must be carried out, since some places can be inaccessible or not visible from the accessible places. Difficulties in surveying the landscape affect the completeness and the spatial representativeness of the landslide inventory and, as a result, inclusion of non-visible areas within a landslide inventory introduces a bias, since the presence or absence of landslides cannot be ascertained in portions of the landscape. This uncertainty has hardly been considered in existing studies that use field-based landslide inventories (Yesilnacar and Topal, 2005; Murillo-García et al., 2015; Wang et al., 2017).

On the other hand, selection of an appropriate terrain subdivision is also a critical step in LSZ analysis. The land surface can be divided into portions following geomorphologic features using terrain units, topographic units, geohydrological units or slope units but also considering thematic layers resulting in unique condition units or administrative units, as well as regular grid cells partitions (Van Den Eeckhaut et al., 2006; Reichenbach et al., 2018). Selection of different mapping units can result in considerable differences in the susceptibility assessment (Carrara et al., 2008). In this work, we considered grid cells and slope units (Carrara et al., 1991, 1995; Guzzetti et al., 2006; Alvioli et al., 2016; Zêzere et al., 2017; Rosi et al., 2018; Ba et al., 2018) and investigated the effect of the different ways of training LSZ models within both types of mapping units.

We propose an automatic and reproducible procedure to delineate the actual area which was explicitly surveyed in preparing a landslide inventory by geomorphological field mapping, i.e. the effective surveyed area (ESA), and to use such relevant information in statistical analyses. The procedure allows us to carry out the calibration of a statistical model within the ESA and then to apply the resulting susceptibility model to the whole area (WA) under investigation. Moreover, we implemented an automatic approach for the delineation of the ESA in a newly developed GRASS GIS module named r.survey.py. The software delineates the theoretical visible areas from the points of view recorded during a field campaign by the GPS tracks. Most importantly, the ESA delineated by r.survey.py is an objective and reproducible portion of the study area directly observed by the geomorphologists, thus allowing us to avoid arbitrary assumptions about which sites were actually surveyed and which ones were not.

This work aims at demonstrating that the calibration of a landslide susceptibility model within the ESA, instead of the WA (the whole study area, encompassing the ESA), enhances the performance of model itself. In a test study area, we calibrated the multivariate logistic regression model for landslide susceptibility in four different ways, combining two different calibration areas (ESA and WA) with two different mapping unit types: (i) a regular grid cell partition with a ground resolution of $5 \mathrm{~m} \times 5 \mathrm{~m}$ and (ii) a slope unit (SU) partition (consisting of irregular terrain subdivisions bounded by drainage and divided lines).

The paper is organised as follows. Section 2 provides an overview of the study area. Section 3 shows the details about data acquisition, in particular the r.survey is described in Sect. 3.3 and SU delineation in Sect. 3.4. Section 4 contains a general description about the multivariate method applied to model landslide susceptibility and the approach followed to validate model results, as well as a detailed description about the set-up of the different model assessments. Results are described in Sect. 5 and are further discussed in Sect. 6. Eventually, our conclusions are drawn in Sect. 7.

\section{Study area}

The Gipuzkoa Province was selected as test study area. It is located in the north of the Iberian Peninsula along the western end of the Pyrenees and covers an area of $1980 \mathrm{~km}^{2}$, with altitude ranging from the sea level to $1528 \mathrm{~m}$ a.s.l. Six watersheds of different size drain the study area and reach the Cantabrian Sea (Fig. 1). The province is characterised by a steep morphology with $55 \%$ of its surface having a slope larger than $15^{\circ}$.

The investigated area is lithologically heterogeneous (Fig. 1), with materials ranging from Paleozoic rocks to Qua- 


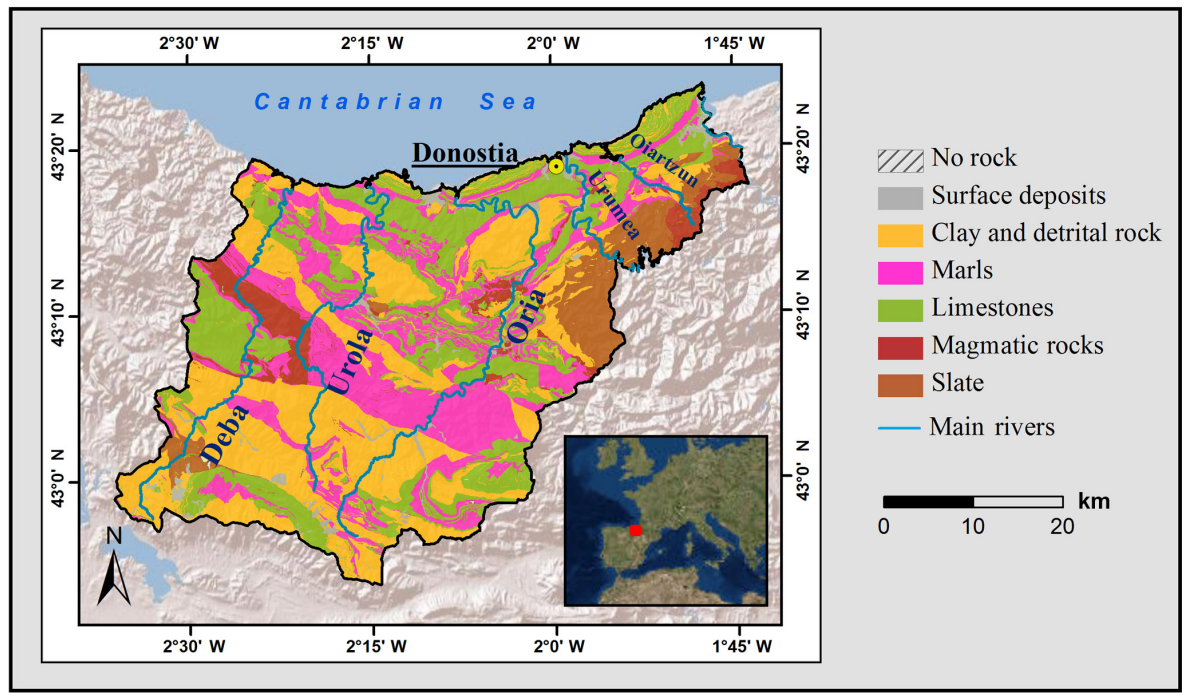

Figure 1. Location of the Gipuzkoa Province study area and simplified lithological map developed according to the original map of the spatial data service of the Basque Country. Coordinates in degrees, Universal Transversal Mercator (UTM) Zone 30N, European Datum ETRS 1989.

ternary deposits (EVE, 2010), and it corresponds to a hilly and mountainous Atlantic landscape (Mücher et al., 2010). The average annual precipitation is $1597 \mathrm{~mm}$ (GonzálezHidalgo et al., 2011) with two maximum periods: $34 \%$ in November-January and $10 \%$ in April. Even though rainfall is the primary triggering factor of shallow landslides (Petley et al., 2005; Alvioli et al., 2018a), anthropogenic slope modifications such as slope clearings and forest extraction activities also strongly affect landslide occurrence (Corominas et al., 2017) in the area.

\section{Data preparation}

\subsection{Landslide inventory}

We prepared a landslide inventory by a direct geomorphological field survey, during the period from June to August 2016. We collected information about the location of each observed landslide, four GPS points (crown, toe and two flanks), photographs, features of the surrounding area and information about the landslide type, according to the Cruden and Varnes (1960) classification. Each documented landslide was drawn and digitised using its four recorded GPS waypoints and photographs as a reference. The QGIS software and Google Earth satellite imagery were used for the purpose. Moreover, and most importantly to define the ESA, we digitised the route followed during the field survey. This information was then elaborated using a GRASS GIS module developed for the purpose and included in this work as the Supplement.

As a result of several field trips, 793 individual landslides were collected; 746 of them were classified as shallow movements (Fig. 2a). Our observations together with the existing literature (INGEMISA, 1995; IDE de Euskadi, 2014; Gipuzkoako Foru Aldundia, unpublished data) confirmed that shallow slides are the most frequent type of landslide in the study area. Consequently, in order to consider only landslides triggered by the same mechanisms, only shallow movements were used to determine landslide presence when defining the dependent variable in the susceptibility assessment. Figure $2 b$ and $c$ show the distribution of landslide sizes, highlighting that a difference of 5 orders of magnitude exists between the smallest and the largest inventoried shallow slide.

\subsection{Explanatory variables}

The selection of the appropriate explanatory variables to build a landslide susceptibility model is an important step (Ayalew and Yamagishi, 2005; Schlögel et al., 2018), and no universal criteria nor guidelines exist for the purpose.

We obtained relevant environmental digital layers from the Spatial Data Service of the Basque Country ${ }^{1}$ and created 13 maps describing the different explanatory variables (see Table 2). To produce derived morphometric continuous variables, such as slope, sinusoidal slope, surface area ratio (SAR), terrain wetness index (TWI), curvature, plan curvature and profile curvature, we used a DEM raster layer with $5 \mathrm{~m} \times 5 \mathrm{~m}$ spatial resolution. sinusoidal slope is a derived morphometric variable proposed by Santacana Quintas (2001) and Amorim (2012) to emphasise the fact that shallow slides typically occur in medium slope areas, while they seldom occur on slopes steeper than $45^{\circ}$. For categorical variables, such as lithology, permeability, regolith thickness,

\footnotetext{
${ }^{1}$ http://www.geo.euskadi.eus (last access: 23 January 2017)
} 

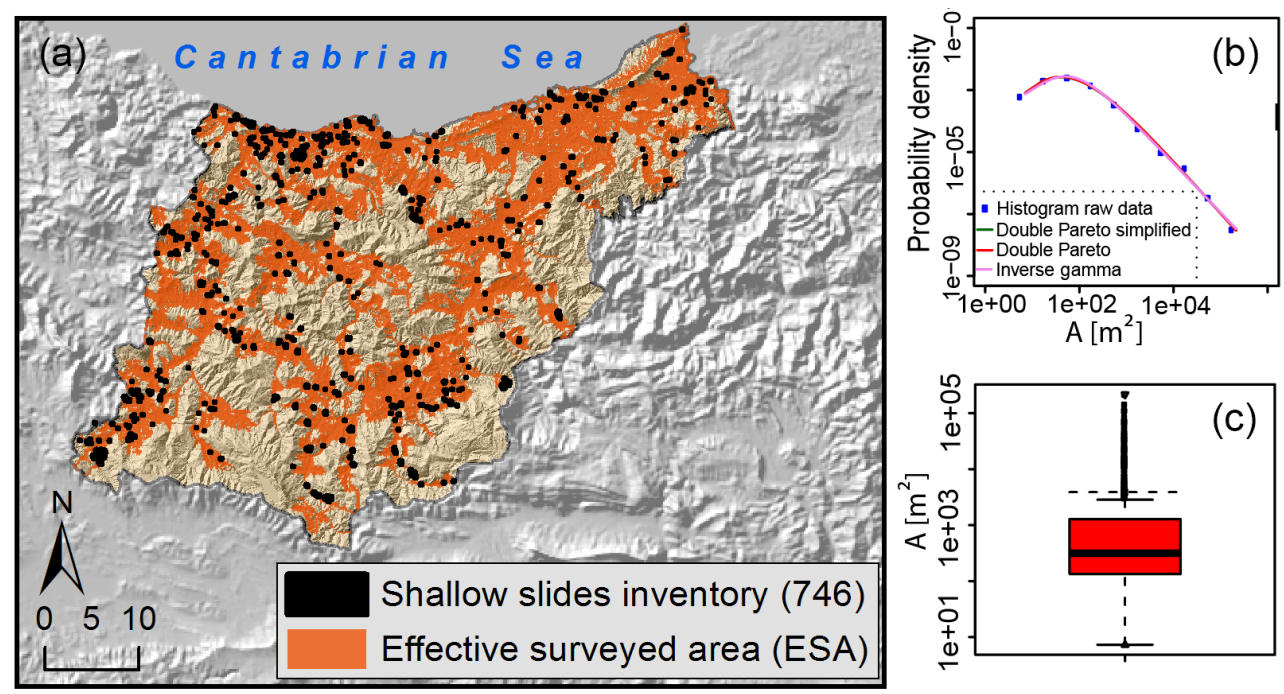

Figure 2. (a) Distribution of the shallow slides inventory along the study area and extension of the effective surveyed area (ESA). (b) Probability density plot of the shallow landslide size (area in $\mathrm{m}^{2}$ ) distribution. (c) Box plot of the same distribution.

land use, vegetation and aspect, we computed frequency ratio (FR) values for each class and used them as relative values for their transformation into continuous variables (Lee and Min, 2001; Yilmaz, 2009; Trigila et al., 2015). We acknowledge that the FR values can vary depending on the portion of the territory considered to be the total area (ESA or WA). In order to perform a direct comparison, we decided to maintain the same FR values (calculated considering the WA) in all regular grid-cell-based susceptibility analyses.

In this work, we first adopted grid cells as mapping units, and we applied a simplified and statistically oriented workflow that ensured that only significant variables were taken into account as well as the non-redundancy of the contributed information by each covariate (Ayalew and Yamagishi, 2005). To do this, the whole set of 13 variables was considered within the LR analysis, and correlation coefficients were computed. We considered two variables to be collinear when their correlation coefficient is greater than 0.5 with a significance level of 0.01 . In such a case, as an objective criterion for variable selection, the variable with the highest $p$ value between the two (see Sect. 4.1) was not taken into consideration in the final run of the susceptibility LR model. Additionally, variables with a $p$ value higher than the threshold of 0.05 were rejected.

Then, considering the variables actually used for the application of the statistical models with grid cells, we have further restricted the set of variables to be used with slope units (see Sect. 5.2).

\subsection{Definition of the effective surveyed area}

In this work we suggest the concept of ESA and training of statistical models therein, as an approach to be used to train a landslide susceptibility model, avoiding assumptions about the presence or absence of landslides in areas not explicitly observed. We delineated the ESA by means of the newly developed GRASS GIS python module r.survey.py (see Supplement). Input data that define the visible area (i.e. ESA in our case) are (i) a sample of points to be considered the points of view, (ii) a DEM of the area and (iii) the maximum visible distance. The sample of points of view, in our case, was defined resampling a given number of points along the recorded path during the field campaigns. This number of points depends on the maximum distance set between them, and together with the selected DEM resolution the results can be directly affected. In a $10 \mathrm{~km}^{2}$ subset of the study area, we tested the software output using (i) the maximum distance between sampled points of 50,100, 200 and $500 \mathrm{~m}$; (ii) the original DEM at $5 \mathrm{~m}$ resolution and resampled versions of the DEM at 20,50 and $100 \mathrm{~m}$ resolution; and (iii) maximum visible distance of $500 \mathrm{~m}$ (the later was dictated by the largest distance between the digitised field path and the farthest landslide pixel in the subset of the study area). Results of the test are summarised in Table 1.

We considered that the best setting was the one which allows the totality of the landslides to be covered using the smallest number of points (larger $D_{\max }$ value) and the lower DEM resolution in order to optimise the calculation time. In our case, considering the whole study area, the maximum visible distance was set to $1100 \mathrm{~m}$, in view that the largest distance between the digitised field path and the farthest landslide pixel was $1092 \mathrm{~m}$. Then, and according to the results of Table 1, we set the maximum sampling distance to $200 \mathrm{~m}$ and adopted a DEM resolution of $100 \mathrm{~m}$.

We can make sense of the numerical values of the parameters used in the r.survey.py module considering that the minimum size $A$ of an object visible from a distance $\Delta$ is given 
Table 1. Results of the setting test of r.survey in a $10 \mathrm{~km}^{2}$ subset of the study area. The best combination of settings is highlighted in bold.

\begin{tabular}{lrrr}
\hline Name & $\begin{array}{r}\text { Resolution } \\
(\mathrm{m})\end{array}$ & $D_{\max }$ & $\begin{array}{r}\text { Percentage of } \\
\text { landslides within }(\%)\end{array}$ \\
\hline Survey 5 & 5 & 50 & 35 \\
Survey 6 & 20 & 50 & 70 \\
Survey 7 & 50 & 50 & 95 \\
Survey 8 & 100 & 50 & 100 \\
Survey 9 & 5 & 100 & 30 \\
Survey 10 & 20 & 100 & 60 \\
Survey 11 & 50 & 100 & 95 \\
Survey 12 & 100 & 100 & 100 \\
Survey 13 & 5 & 200 & 30 \\
Survey 14 & 20 & 200 & 55 \\
Survey 15 & 50 & 200 & 85 \\
Survey 16 & $\mathbf{1 0 0}$ & $\mathbf{2 0 0}$ & $\mathbf{1 0 0}$ \\
Survey 17 & 5 & 500 & 0 \\
Survey 18 & 20 & 500 & 35 \\
Survey 19 & 50 & 500 & 60 \\
Survey 20 & 100 & 500 & 95 \\
\hline
\end{tabular}

by Rodrigues et al. (2010) and Minelli et al. (2014):

$A=\frac{25 \Delta^{2}}{c}$,

where $c$ is a steradian to square minutes conversion factor, $c \simeq 1.18 \times 10^{7}$. Using $\Delta=1100 \mathrm{~m}$ in Eq. (1), we get $A=$ $2.6 \mathrm{~m}^{2}$, meaning that the smallest landslide in our inventory, with size $7.3 \mathrm{~m}^{2}$, would actually be identifiable from at least one point along the route if the landslide sits within the ESA. The resulting ESA covers $44.24 \%$ of the entire study area and it is shown in Fig. 2a.

\subsection{Slope unit delineation}

For SU delineation we have adopted the r.slopeunits software described in Alvioli et al. (2016). The software is a GRASS GIS module, as is the r.survey.py code presented in this work, and it was designed for the automatic and adaptive delineation of SUs given a DEM and a set of user-defined input parameters. The code can be used to produce several SU partitions, using different combinations of the input parameters, which can thus be tuned according to user-defined criteria. We partially followed Alvioli et al. (2016), in that we selected the best SU partition considering the quality of terrain aspect segmentation. In addition, we performed preliminary tests using the LR susceptibility model, showing that the use of very small SUs provides unrealistic results, which can be understood considering the limited variability of variables within such small SU polygons. We concluded that, in the case of the Gipuzkoa Province the most suitable SU partition for landslide susceptibility zonation should be obtained with the following r.slopeunits input parameters: flow accumula- tion area threshold $t=1 \mathrm{~km}^{2}$, minimum SU planimetric area $a=0.15 \mathrm{~km}^{2}$, minimum circular variance of terrain aspect within each SU $c=0.2$, reduction factor $r=5$ and threshold value for the cleaning procedure cleansize $=0.025 \mathrm{~km}^{2}$. As a result, we obtained a set of SUs which range in size from 0.026 to $3.6 \mathrm{~km}^{2}$ with an average of $0.28 \mathrm{~km}^{2}$. A discussion of SU delineation and optimisation of input parameters can be found in Alvioli et al. (2016) and Schlögel et al. (2018), and it is beyond the scope of this work.

\section{Modelling framework}

We prepared four landslide susceptibility maps (LS maps), by means of a multivariate LR model. Classification performances were measured by means of a set of validation tests explained in the following sections. We prepared the first two maps using $5 \mathrm{~m} \times 5 \mathrm{~m}$ regular grid cells as mapping units. The two maps differ because in one case the LR model was calibrated within the WA, and in the other case within the ESA (described in Sect. 3.3). The third and fourth LS maps, instead, were prepared with different mapping units, namely with SUs (described in Sect. 3.4) instead of grid cells, where calibration data were also changed considering data within WA in one case and within ESA in the other. We end up with four maps, which we name as follows: WA-PM (whole-area pixel map), ESA-PM (effective surveyed area pixel map), WA-SUM (whole area of the slope units map) and ESASUM (effective surveyed area of slope units map).

\subsection{Logistic regression}

We used logistic regression (Hosmer Jr. et al., 2013), one of the multivariate statistical approaches available in the LAND-SE software (Rossi and Reichenbach, 2016), to build the landslide susceptibility model in the test study area. The method is the most used in the scientific literature (Reichenbach et al., 2018) and proved to be useful and reliable in several studies (Nefeslioglu et al., 2008; Van Den Eeckhaut et al., 2012; Trigila et al., 2015). The LR model works with either continuous or categorical independent variables, or a combination of the two types, regardless of whether they are normally distributed or not (Costanzo et al., 2014).

The mathematical relationship between the dependent dichotomous variable (presence or absence of a landslide in the mapping unit; $Y$ in the following) and the $n$ independent variables (e.g. slope, lithology; $X_{1}, \ldots, X_{n}$ ), within the LR model, reads as follows:

$Y=\beta_{0}+\beta_{1} X_{1}+\ldots+\beta_{n} X_{n}$,

where $\beta_{0}$ is the intercept of the model and $\beta_{1}, \ldots, \beta_{n}$ the linear regression estimate coefficients. The independent (explanatory) variables, $X_{1}, \ldots, X_{n}$, included in our case both continuous and categorical layers (the latter were previously transformed into continuous variables, as described in 
Table 2. Set of environmental variables introduced for the whole-area pixel-based (WA-PM) and effective surveyed-area pixel-based (ESAPM) model calculation, together with the significant $p$-value estimate corresponding to each explanatory variable (cf. Sect. 4.1). The best predictors were labelled with an asterisk.

\begin{tabular}{|c|c|c|c|}
\hline Name & Description & \multicolumn{2}{|l|}{ Significant $p$ value } \\
\hline Continuous & & WA-PM & ESA-PM \\
\hline Slope & The slope gradient in degrees. & $1.17 \times 10^{-189}$ & $1.06 \times 10^{-111}$ \\
\hline Sinusoidal slope & $\begin{array}{l}\text { The sinusoidal mathematical transformation applied to the slope } \\
\text { variable (Amorim, 2012) }\end{array}$ & $1.00 \times 10^{-155}$ & $7.57 \times 10^{-134 *}$ \\
\hline Surface area ratio & $\begin{array}{l}\text { The relation between the theoretical volume and the surface of } \\
\text { each pixel. }\end{array}$ & $3.743 \times 10^{-203 *}$ & $1.89 \times 10^{-99}$ \\
\hline Terrain wetness index & $\begin{array}{l}\text { The spatial distribution of soil moisture or saturation (Yilmaz, } \\
\text { 2009) }\end{array}$ & $9.864 \times 10^{-10 *}$ & 0.126807342 \\
\hline Curvature & The spatial variation of the slope gradient. & 0.909592654 & 0.525989188 \\
\hline Plan curvature & $\begin{array}{l}\text { The curvature of the surface perpendicular to the direction of } \\
\text { the maximum slope. }\end{array}$ & 0.9094261 & 0.525836679 \\
\hline Profile curvature & $\begin{array}{l}\text { The curvature of the surface in the direction of the maximum } \\
\text { slope. }\end{array}$ & 0.909605174 & 0.526032985 \\
\hline \multicolumn{4}{|l|}{ Categorical } \\
\hline Lithology & $\begin{array}{l}\text { The original categories have been reclassified by expert criteria } \\
\text { (Geoeuskadi). }\end{array}$ & $0 *$ & $0 *$ \\
\hline Permeability & $\begin{array}{l}\text { The original categories have been reclassified by expert criteria } \\
\text { (Geoeuskadi). }\end{array}$ & $1.496 \times 10^{-33 *}$ & $7.632 \times 10^{-72 *}$ \\
\hline Regolith thickness & $\begin{array}{l}\text { The layer for the study area has been obtained from the litho- } \\
\text { logical map (Geoeuskadi). }\end{array}$ & $0^{*}$ & $0 *$ \\
\hline Land use & $\begin{array}{l}\text { The original categories have been reclassified by expert criteria } \\
\text { (Geoeuskadi). }\end{array}$ & $5.14 \times 10^{-291}$ & $1.42 \times 10^{-87}$ \\
\hline Vegetation & $\begin{array}{l}\text { The original categories have been reclassified by expert criteria } \\
\text { (Geoeuskadi). }\end{array}$ & $0 *$ & $1.596 \times 10^{-173 *}$ \\
\hline Aspect & $\begin{array}{l}\text { It represents the downslope direction measured in degrees clas- } \\
\text { sified in nine classes. }\end{array}$ & $0 *$ & $0^{*}$ \\
\hline
\end{tabular}

Sect. 3.2); see Table 2 for the full list of variables used in this work. Calibrating an LR model amounts to selecting numerical values for the $\left\{\beta_{i}\right\}_{i=1}^{i=n}$ coefficients in Eq. (2) that maximise the agreement between model output, i.e. landslide probability:

$P=\frac{1}{1+e^{-Y}}$,

and empirical landslide data, in a training area. The same values of the coefficients can then be used to validate the model prediction skills in a different area, where landslide conditions are unknown to the model but the same explanatory variables layers exist.

In addition to the $\beta$ coefficients, the LR method offers a significant $p$ value for each explanatory variable. The implementation of the $\mathrm{glm}$ function of the $\mathrm{R}$ programming language library ${ }^{2}$, used in the LAND-SE software, is such that it is possible to investigate the estimated standard error of a $t$ statistic for the null hypothesis of each of the coefficients of the linear model. The $p$ value represents the probability for

\footnotetext{
${ }^{2}$ https://www.r-project.org/ (last access: 6 March 2017)
}

the parameter to be zero: for $p$ values smaller than 0.05 the null hypothesis (vanishing coefficient) is rejected; thus the associated variable is significant for the final result. So, the $p$ value can be considered an objective indicator for the selection of the most relevant variables to be used in the statistical model (Schlögel et al., 2018).

\subsection{Evaluation of model performance}

The performance of statistical susceptibility models, i.e. of multivariate binary classifiers, can be evaluated by comparing their predictions with the landslide data used in the model calibration/training step (i.e. model fitting performance) or with independent landslide data (i.e. model prediction performance). The definition of training and validation input samples is crucial to detect how well each model fits input data but also how good the model is at predicting new data.

The statistical metrics commonly used in the literature (Corominas and Mavrouli, 2011; Van Den Eeckhaut et al., 2006; Lombardo et al., 2015; Reichenbach et al., 2018) for that purpose are (i) confusion matrices (contingency tables) and their graphical representation (four-fold or contingency 
plots), (ii) receiver operating characteristic (ROC) curves and their associated area under curve (AUC) value, (iii) classification error plots and (iv) Cohen's kappa index.

Four-fold (or contingency) plots are visual representations of the confusion matrices reporting the percentages of the true positives (TP), true negatives (TN), false positives (FP) and false negatives (FN). ROC curves are a more complex representation of the classification performance based on different probabilistic threshold values. The area under the ROC curve (AUC) is an indicator of the model performance in predicting landslide susceptibility. AUC values vary between 0 and 1, with higher values indicating better prediction skills (Fawcett, 2006).

To estimate the uncertainty associated with the landslide susceptibility value assigned to each mapping unit, it is possible to run multiple instances of the LR model varying, randomly, the input data. In each run, the input is prepared by sampling the original training data set with a bootstrap technique, consisting of a random sampling with replacement (Efron, 1992; Davison and Hinkley, 1997; Rossi et al., 2010; Rossi and Reichenbach, 2016). Classification error plots summarise the distribution of multiple results and show the mean probability estimate of landslide spatial occurrence for each mapping unit ( $x$ axis), ranked from low (left) to high (right) values, related to the variation of the model estimate ( $y$ axis), measured by 2 standard deviations $(2 \sigma)$ of the probability estimates obtained by the different model runs (Guzzetti et al., 2006). The parabolic model fitting equation resulting from the point cloud (i.e. using a non-linear least square method), analytically describes the overall model prediction performance variability. Cohen's kappa index $(\kappa)$ is an additional measure of the reliability of a classification model (Cohen, 1960; Rossi et al., 2010), with higher values that also indicate a more accurate prediction skill.

In this study the probability of landslide occurrence resulting from each model estimate (trained either within the ESA or within the WA) and for each considered mapping unit (either grid cells or slope units) was reclassified in five landslide susceptibility classes, which were labelled as very low (for susceptibility values in the range $0-0.2$ ), low $(0.2-0.45$ ), medium (0.45-0.55), high $(0.55-0.8)$ and very high $(0.8-1)$.

Moreover, in order to spatially identify the pairwise matching degree between different model estimates, we additionally adopted a simplified classification of the landslide susceptibility. Each mapping unit was reclassified as stable or unstable considering a threshold value of 0.5 . The different maps, all of which were prepared with the same mapping unit partition, were overlapped. Then, the mismatch degree between grid cell and SU susceptibility maps was quantified in terms of number of mismatched mapping units and overall mismatched area.

\subsection{Data selection for landslide susceptibility}

The DEM available for the study area consists of $7.91 \times 10^{7}$ cells with $5 \mathrm{~m}$ resolution. For landslide susceptibility assessment, both using grid cells (i.e. pixels) and SUs, we prepared raster layers corresponding to each available explanatory variable, aligned to the DEM grid cells.

We devised a rigorous sampling procedure to minimise possible statistical biases during training/validation partition. The procedure is slightly different for the grid cell and SU mapping units.

In the first case, a grid cell is considered unstable if it is located within any landslide polygon and stable if it is outside the landslide boundaries. In the second case, an SU was considered unstable depending on the percentage of landslide area present within it. In any case, the $75 \%$ of the unstable mapping units together with a similar number of stable mapping units were used to train the LR model, and the remaining $25 \%$, also together with a similar number of stable mapping units for validation. The choice of an equal number of stable and unstable mapping units was done on purpose, and it is the standard procedure required by the LAND-SE software for landslide susceptibility assessment, because the LR model requires a balanced data set, in which the number of stable and unstable cases are similar (Felicísimo et al., 2013; Costanzo et al., 2014).

For regular grid-cell-based models, we selected at random 558 landslides (75\%) for model training and converted them into raster layers (84 623 unstable pixels). The remaining 188 landslides $(25 \%)$ used for validation were also rasterised (29 247 unstable pixels). This is at variance with the usual random selection of unstable pixels, in which a given percentage of grid cells are sampled within landslide polygons. Here we select whole landslides and consider all the pixels encompassed by the landslide bodies as training/validation samples. We ran the experiment with three different training/validation random sets, containing the above percentages. This exercise allowed us to confirm that the random selection of the landslide inventory does not affect the model results in a relevant way, because in all the cases the model classification performances were very similar. In order to choose one single data set for further comparative analyses, the data set with the best classification result was selected. Then, training sets were selected as follows: 84623 unstable pixels and an equal number of stable pixels were selected as training sets. Two different sets were selected at random, first within WA and then within ESA. We made sure that unstable pixels were exactly the same in the two cases, because we wanted the only difference to be that the stable pixels were sampled within the WA in the first case and within the ESA in the second case. Finally, in order to guarantee the comparability of the prediction performances, one unique validation sample was created as follows: the remaining 29247 unstable pixels together with an equal number of stable pixels selected at random within the remaining stable pixels within the ESA. 
Concerning the SU-based models, we first partitioned the study area into 6907 SUs with the technique outlined in Sect. 3.4. SU boundaries do not match those of the dependent or explanatory variables layers, allowing the presence of different classes or values inside each SU. Moreover, the presence of one single landslide pixel within a slope unit was not considered enough to label this SU as unstable. Therefore, instead of arbitrarily defining a given threshold value in order to consider an SU as unstable, we decided to use the overall landslide density in the WA. For this reason, we considered to be unstable those SUs containing $0.15 \%$ or more unstable pixels and stable otherwise. We used as explanatory variables the mean and the standard deviation of the morphometric variables for each SU and the percentage of the area covered by each class of the categorical layers. In 304 cases the SU contained $0.15 \%$ or more unstable pixels, so we selected at random 228 of them $(75 \%)$ for training, and the remaining $76(25 \%)$ were used for validation. Like in grid cell approaches, we created two different training samples where unstable SUs were exactly the same, and only the stable SUs vary in each case. The first training sample includes 228 stable SUs selected at random along the WA. The second training sample includes an equal number of stable SU units selected at random among those that at least partially overlap the ESA. Additionally, 76 SUs labelled as unstable were selected from the whole set for validation. The validation sample was completed by adding a random selection of the same number of SUs labelled as stable and which at least partially overlap the ESA. Thus, the validation sample contained 152 SUs (76 unstable and 76 stable).

Eventually, since the ESA is an approximation of the real surveyed area, we stress that we always selected stable mapping units for validation only if they are fully or partially within the ESA, because no evidence exists that a mapping unit falling entirely outside the ESA is actually free from landslides. Moreover, if a portion of an SU falls within the ESA, it implies that at least one part of the SU was observed. Therefore, using this approach, we can remove at least those SUs that were not surveyed at all.

\section{Results}

\subsection{Susceptibility maps using grid cells}

We ran the LR model using the pixel-based data sets twice: once using the entire training pixel sample and once using the effective training pixel sample as dependent variables. We defined the obtained results as whole-area pixel map (WAPM) and effective surveyed-area pixel map (ESA-PM).

In both WA-PM and ESA-PM, we first used the same 13 explanatory variables listed in Table 2, and then we selected for each model assessment the most relevant explanatory variables considering the collinearity between each pair of variables and the significance ( $p$ value) of the regression estimates (see Sect. 3.2). As a result, for each case, only the variables marked with an asterisk in Table 2 were introduced in the final LR analysis.

Using the validation pixel sample, we evaluated the prediction skills of the pixel susceptibility maps. Inspection of the four-fold or contingency plots (Fig. 3a, d) reveals that WA-PM correctly predicted the $63.58 \%(\mathrm{TP}+\mathrm{TN})$ of the observed unstable and stable mapping units, whereas ESA-PM was capable of correctly predicting a higher number of mapping units $(65.45 \%)$. The ROC curves (Fig. 3b, e) also indicate better prediction skills in ESA-PM $(\mathrm{AUC}=0.7)$ than in WA-PM $(\mathrm{AUC}=0.68)$ and the same happens for the Cohen's kappa index (Fig. 3; $k=0.309$ versus $k=0.272$ ). Moreover, the classification error plots (Fig. 3c, f) provide an estimate of the error associated with the predicted susceptibility values, which do not exceed 0.1 standard deviations in any case, highlighting the reliability of the results. And finally, the mutual mismatch map (Fig. 5e) shows that $14.8 \%$ (corresponding to an extension of $293 \mathrm{~km}^{2}$ ) of the mapping units flipped their landslide susceptibility class in WA-PM and ESA-PM.

\subsection{Susceptibility maps using slope units}

Due to the subdivision of categorical variables in classes and to the use of mean and standard deviation of morphometric variables, the introduction of the original 13 explanatory variables would result in 56 new variables in which many of them (all those classes belonging to the same categorical variable) would be highly correlated. For this reason, the variable selection approach used in the pixel-based case is not viable when working with SUs and a specific variable selection approach for SU models would require further investigation. Thus, for this work, the most appropriate set of explanatory variables, among those considered to be the most relevant in pixel-based model assessment, was selected by expert criteria. Considering this set of variables as a starting point, we selected new sets of explanatory variables to evaluate landslide susceptibility using SUs, i.e. to calculate the whole-area slope unit map (WA-SUM) and the effective area slope unit map (ESA-SUM). Taking into account that the automatic procedure for the SU definition already included the flow accumulation calculation, used for TWI estimation, and the aspect component, we rejected aspect and TWI to avoid spurious correlations. We selected the following set of variables used to produce both pixel-based maps such as lithology, permeability, regolith thickness and vegetation, and we added slope. The reason for choosing slope over sinusoidal slope or SAR is due to the fact that these two are derivative variables of the former. Moreover, we consider slope more suitable feature to describe the average morphology within SU than sinusoidal slope or SAR, so we decided to select it in order to simplify our interpretation of the results.

Using the validation SU sample, we assessed the prediction skills of the SU maps. For the WA-SUM the $65.13 \%$ of the 152 validation mapping units were correctly classified 
Whole area pixel map (WA-PM)

\begin{tabular}{|c|c|c|c|}
\hline Cohen's $k$ & $\mathrm{AUC}_{R O C}$ & Overall accuracy & Overall error rate \\
\hline 0.272 & 0.68 & $63.58 \%$ & $36.42 \%$ \\
\hline
\end{tabular}

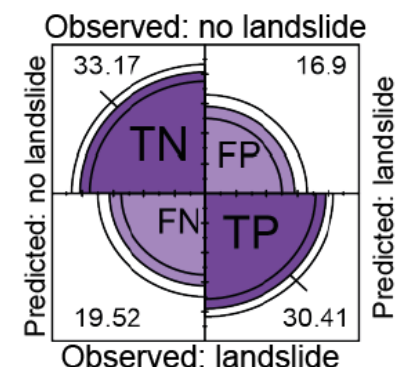

(a)

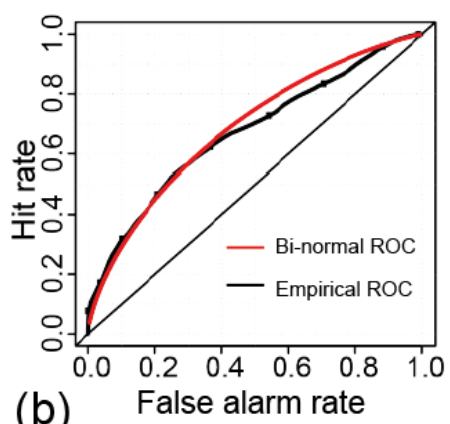

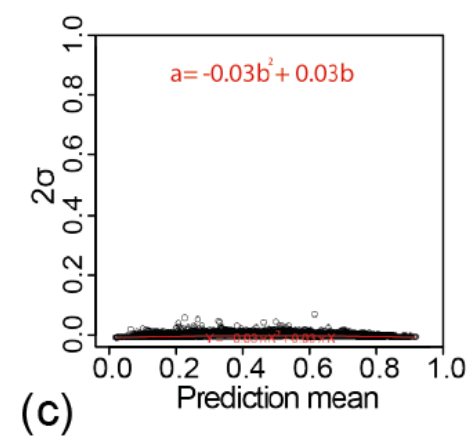

(c)

\section{Effective surveyed area pixel map (ESA-PM)}

\begin{tabular}{|c|c|c|c|}
\hline Cohen's $k$ & $\mathrm{AUC}_{R O C}$ & Overall accuracy & Overall error rate \\
\hline 0.309 & 0.7 & $65.45 \%$ & $34.55 \%$ \\
\hline
\end{tabular}

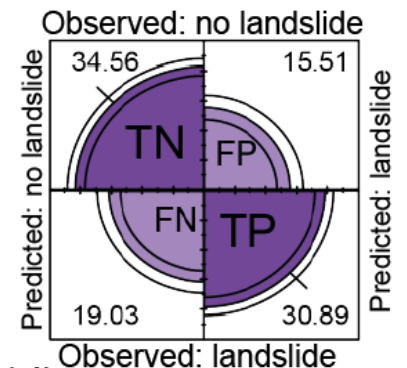

(d)
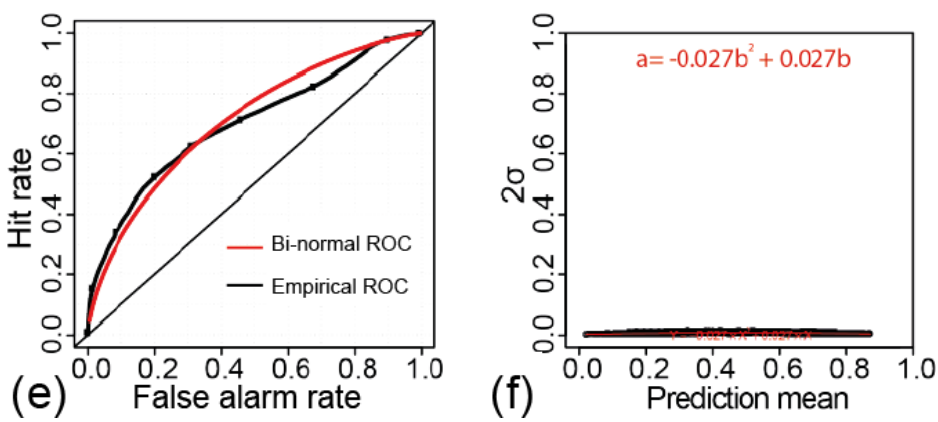

Figure 3. Pixel-based LR models prediction performance results: summary tables of the Cohen's kappa index, area under the ROC curve $(\mathrm{AUC})$, overall accuracy $((\mathrm{TP}+\mathrm{TN}) /(\mathrm{TP}+\mathrm{TN}+\mathrm{FP}+\mathrm{FN}))$ and overall error rate $((\mathrm{FP}+\mathrm{FN}) /(\mathrm{TP}+\mathrm{TN}+\mathrm{FP}+\mathrm{FN}))$. (a, d) Four-fold or contingency plots; (b, e) ROC curves; (c, f) classification error plots and the quadratic regression fit curves (red line).

$(\mathrm{TP}+\mathrm{TN})$ (Fig. 4a). The ROC curve provides $\mathrm{AUC}=0.69$, and the corresponding Cohen's kappa is $k=0.302$ (Fig. 4b). Concerning the classification error plot (Fig. 4c), it can be observed that in the SUs with high and low landslide susceptibility probability (probability $>0.8$ and $<0.2$ ) the $2 \sigma$ value stays below 0.2 , but variability in the estimates becomes larger for intermediate susceptibilities. This reveals a considerable variation in the stable/unstable classification of the territory, which implies low reliability, at least for the intermediate probabilities (Guzzetti et al., 2006). For the ESASUM, $63.82 \%$ of the 152 validation mapping units were correctly classified $(\mathrm{TP}+\mathrm{TN})$ (Fig. 4d) with $\mathrm{AUC}=0.71$, slightly larger with respect to the other SU model assessment, whereas the Cohen's kappa index performed slightly worse, being $k=0.276$ (Fig. 4). The classification error plot shows a considerable variation in intermediate probabilities (Fig. 4f), while the uncertainty is lower for high and low probabilities.
Nevertheless, the quadratic fit curves indicate a lower overall variability for ESA-SUM than for WA-SUM.

Visual inspection of the SU susceptibility maps (Fig. 5b, d) shows similarities between WA-SUM and ESA-SUM. The difference is graphically presented through the mismatch map (Fig. 5f), where $12.6 \%$ of the mapping units (corresponding to an extension of $247 \mathrm{~km}^{2}$ ) change their landslide susceptibility class, between WA-SUM and ESA-SUM.

\section{Discussion}

The number of scientific publications focusing on landslide susceptibility zonation has notably increased over the last decades (Gutiérrez et al., 2010; Rossi and Reichenbach, 2016; Liberatoscioli et al., 2017; Valagussa et al., 2017; Zhou et al., 2018; Reichenbach et al., 2018) and, nowadays, there is a huge variety of applications and comparisons which provide an enormous range of approaches with which to prepare 
Whole area slope unit map (WA-SUM)

\begin{tabular}{|c|c|c|c|}
\hline Cohen's $k$ & $\mathrm{AUC}_{R O C}$ & Overall accuracy & Overall error rate \\
\hline 0.302 & 0.69 & $65.13 \%$ & $34.87 \%$ \\
\hline
\end{tabular}

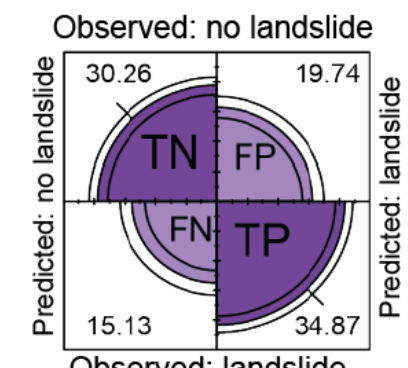

(a)

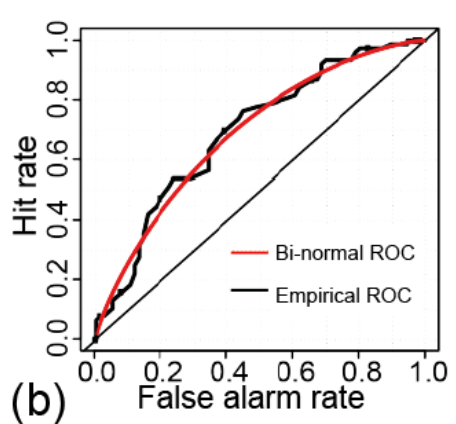

(b)

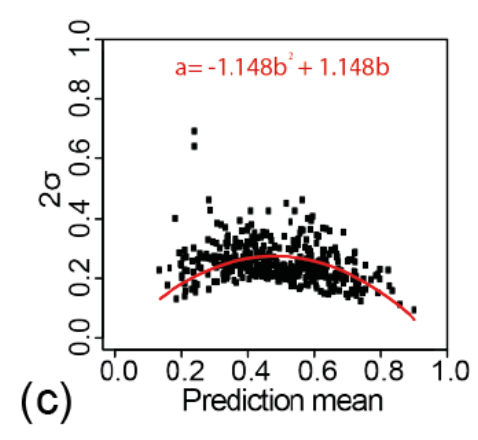

(c)

\section{Effective surveyed area slope unit map (ESA-SUM)

\begin{tabular}{|c|c|c|c|}
\hline Cohen's $k$ & $\mathrm{AUC}_{R O C}$ & Overall accuracy & Overall error rate \\
\hline 0.276 & 0.71 & $63.82 \%$ & $36.18 \%$ \\
\hline
\end{tabular}
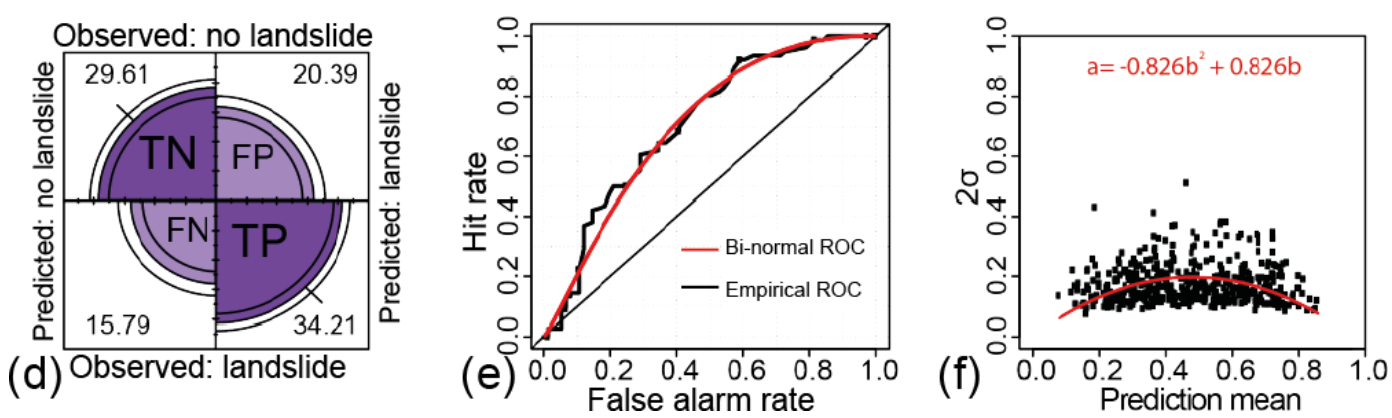

Figure 4. SU-based LR models prediction performance results: summary tables of the Cohen's kappa index, area under the ROC curve $(\mathrm{AUC})$, overall accuracy $((\mathrm{TP}+\mathrm{TN}) /(\mathrm{TP}+\mathrm{TN}+\mathrm{FP}+\mathrm{FN}))$ and overall error rate $((\mathrm{FP}+\mathrm{FN}) /(\mathrm{TP}+\mathrm{TN}+\mathrm{FP}+\mathrm{FN}))$. $(\mathbf{a}, \mathbf{d}) \mathrm{Four}-$ fold or contingency plots; (b, e) ROC curves; (c, f) classification error plots and the quadratic regression fit curves (red line).

a landslide susceptibility map. Differences between these approaches can be summarised in (i) the type of landslide inventory, (ii) the environmental variables used, (iii) the mapping unit partition, (iv) the method used to prepare susceptibility maps and (v) the scale of application. The existence of such a big production of papers investigating these aspects is proof that no fully consolidated standard exists for all the steps involved in landslide susceptibility analysis.

In this work, we showed that the information contained in a field-based landslide inventory for landslide susceptibility analysis should be critically examined, also in combination with the mapping unit of choice.

A fieldwork-based landslide inventory is by definition a source of uncertainty in statistical analysis, owing to various reasons, including mapping errors, accuracy, subjectivity and others. The focus of this work is the analysis of an additional uncertainty due to use of field mapping, namely the fact that it is impossible to ensure that the study area was surveyed in a homogeneous way. An objective delimitation of the surveyed area by means of the ESA, proposed in this paper along with a module to objectively delineate the ESA (see Supplement), is one way to reduce this uncertainty.

The hypothesis tested in this work is that any statistical landslide susceptibility model trained inside the ESA is by definition more correct than considering the entire study area for training the model. The statement was borne out by the results of multivariate LR model calculations. We acknowledge that the ESA is only an approximation of the real surveyed area, though much more realistic than usage of the whole study area. Our definition of the ESA depends on the maximum distance between points along the field trips paths and the selected resolution of the DEM. Preliminary tests in a reduced portion of the territory provided the most suitable settings for a satisfactory definition of the ESA in the particular case of Gipuzkoa Province (Sect. 3.3). 

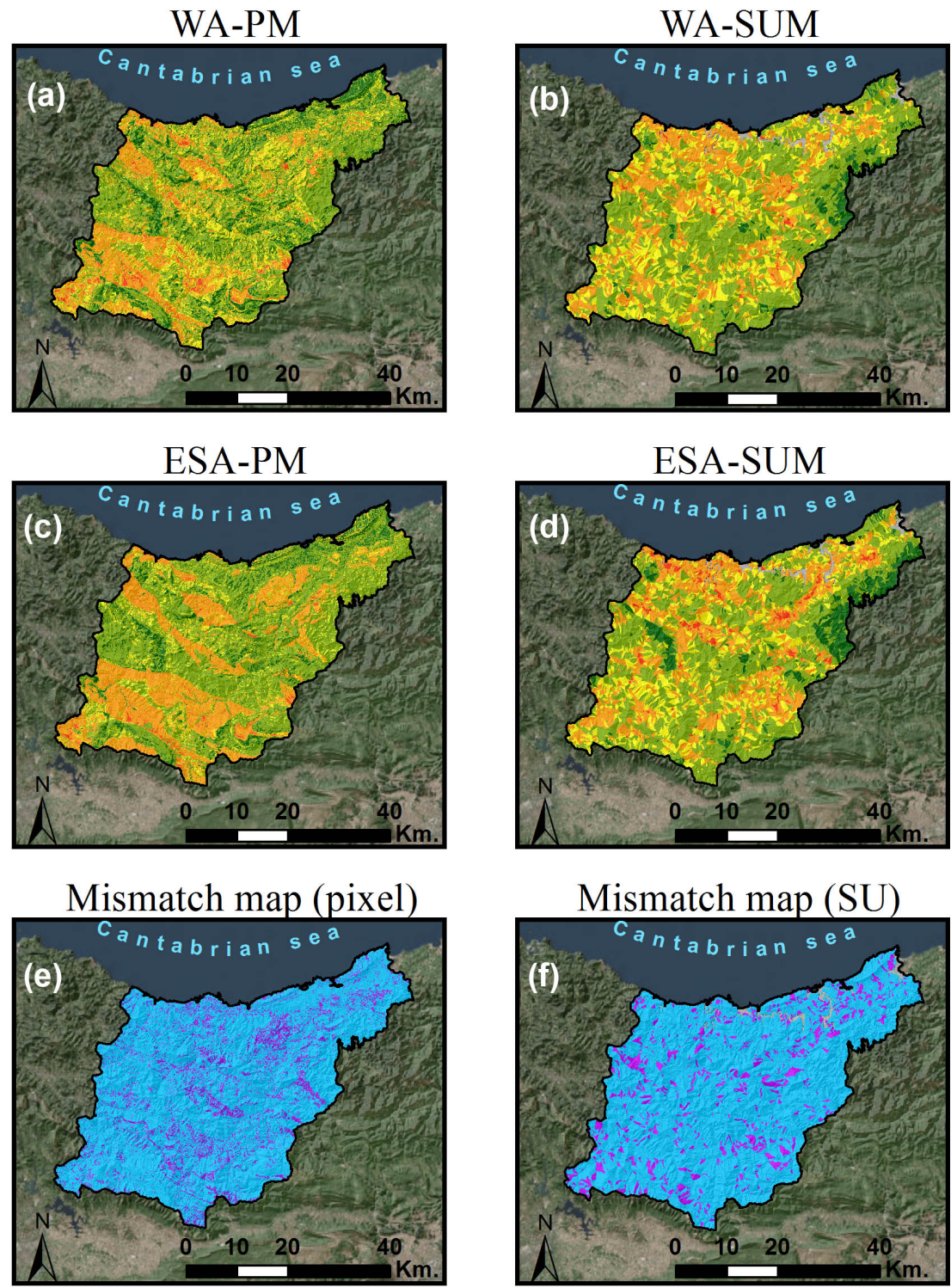

\section{Landslide susceptibility probability classes}

Very low $\square$ High
$\square$ Low
$\square$ Medium

\section{Mismatch map legend}

Match

Mismatch

Figure 5. (a-d) Landslide susceptibility maps represented in five classes for WA-PM, WA-SUM, ESA-PM and ESA-SUM. (e, f) Mismatch maps representing the spatial distribution of the mapping units differently classified using ESA between pixel models and slope unit models.

In the case of the pixel-based susceptibility maps, the metrics of model prediction performances are in agreement with our main statement about the relevance of ESA. As a matter of fact, all the validation performance tests (confusion matrix metrics, the area under the ROC curve and Cohen's kappa index) present an improvement if the stable pixels used for training the LR model are selected within the ESA (like in ESA-PM; Fig. 3a) than if they are taken from the WA (like in WA-PM; Fig. 3b). In addition, the almost flat classification error plots in both cases (Fig. 3c, f) show high stability of model results. The spatial distribution of the susceptibility classes are different as well between ESA-PM and WA- 
PM (see Fig. 5a, c), and these differences are highlighted in the mutual mismatch map (Fig. 5e). Another difference between the two pixel maps is the set of explanatory variables selected as predictors. The variable selection approach presented in this paper and previously adopted in a similar way in Schlögel et al. (2018) demonstrated its effectiveness and capability in detecting the presence of redundant information, as well as offering an objective way of choosing between collinear explanatory variables.

In the case of SU-based susceptibility maps, validation metrics do not present us with clear-cut results as in the pixel-based maps. As a matter of fact, AUC performs better in ESA-SUM, while the confusion matrix and Cohen's kappa index present higher prediction performance in WASUM (Fig. 4). The classification error plots show considerable variation in intermediate susceptibility probability values, but the quadratic fit curves suggest a slightly lower variability in ESA-SUM (Fig. 4c, f). We interpret these results as an indication of a smaller effect that proper usage of the ESA can have in SU-based susceptibility maps with respect to pixel-based maps. Despite the small difference in model prediction performance between WA-SUM and ESA-SUM, the reduction of the mismatch degree (Fig. 5f) suggests that usage of the ESA is equally recommendable for SU susceptibility maps carried out by fieldwork landslide inventories.

The pixel- and SU-based maps obtained within the method presented in this work are inherently different from a conceptual point of view. We maintain that an SU-based map probably represents a better option, because SUs bear a clear relation with topography, reduce mapping errors and are more useful for practical (planning) purposes. Nevertheless, for the sake of completeness and to show differences between the two approaches, we discussed pixel-based and SUbased maps independently. The uncertainty introduced by a fieldwork-based landslide inventory can be mitigated by using SUs, resulting in more similar susceptibility maps and validation performances in WA-SUM and ESA-SUM than in pixel models.

Moreover, since the threshold value for distinguishing stable and unstable SUs could affect the LR model performances, we performed a sensitivity test to evaluate the LR models for both the WA and ESA, using the presence or absence of different thresholds. We carried out calculations using as a threshold the 5 th percentile $\left(P_{5}\right.$, threshold $\left.0.013 \%\right)$, the 50th percentile ( $P_{50}$, threshold $\left.0.265 \%\right)$ and the 90th percentile $\left(P_{90}\right.$, threshold $\left.4.5 \%\right)$ of areal landslide distribution, along with the average landslide density calculated within the ESA, i.e. $0.33 \%$. We observed that, for all the cases except $P_{90}$, the model tests showed better performance for ESASUM than for WA-SUM, which is proof that the conclusions obtained following any approach were indistinguishable. We note that, because of the high threshold defined in $P_{90}$, the model was trained with a very small sample of unstable SUs, which gives the result a very poor reliability. On the other hand, in the $P_{5}$ case, the imbalance does not take place, since each SU with at least one landslide pixel belongs to the unstable class, resulting in a minimum yet relevant number of unstable SUs. Therefore, we maintain that the results of the test confirm that SUs mitigate the relevance of the calibration area (ESA versus WA) when building an SU-based susceptibility model with a field-based landslide inventory, independently of the landslide presence threshold value. However, we acknowledge that the search of an optimal threshold value that ensures a balanced sample is a relevant point, though it is beyond the scope of this work.

\section{Conclusions}

We explored the effects of training an LR classifier (Rossi and Reichenbach, 2016) for landslide susceptibility zonation within the area that was actually surveyed at landslide mapping time, the ESA and the extended study area, WA, encompassing the ESA. We prepared four susceptibility maps combining variables (cf. Eq. 2 and Table 2) sampled strictly within the ESA or from the WA with two different mapping unit partitions, i.e. $5 \mathrm{~m} \times 5 \mathrm{~m}$ grid cells and slope units (Alvioli et al., 2016), delineated for the purpose.

A straightforward comparative analysis using standard prediction performance metrics revealed that the ESA-based approach is better than the WA-based approach, at least in grid-cell mapping-unit-based approaches for the training area (i.e. within the ESA or WA). By introducing different mapping units in the comparison, we further found that using slope units slightly reduces the gap between results obtained training a statistical model within the ESA versus WA. Thus, the capacity of the slope-unit-mapping subdivision to mitigate this error was demonstrated to be a suitable alternative to the conventional pixel-based approaches.

The results illustrated above support the following statements:

i. Working with pixel mapping units and training a statistical classifier for LSZ within the ESA is the correct approach for reducing the uncertainty inherent to the landslide inventory.

ii. By working with slope unit terrain partition this uncertainty can be mitigated, even though it is still advantageous to train the LS model within the ESA.

iii. Use of the ESA should be considered if sufficient information is available in preparing landslide susceptibility maps with any multivariate statistical model.

iv. Collecting information about the path followed during field campaigns for landslide mapping is a meaningful procedure for estimating the ESA at model assessment time using the GRASS GIS module r.survey.py presented in this work. 
We acknowledge that the overall performances of the landslide susceptibility maps presented in this paper are of moderate to low prediction capacity, with AUC values ranging between 0.68 and 0.71 and an overall accuracy which hardly overcomes $65 \%$ in the best case (Figs. 3 and 4). This could be due to (i) the lack of a more complete landslide inventory (Guzzetti et al., 2012; Malamud et al., 2004) or (ii) the use of not up-to-date thematic layers. Nevertheless, the preparation of a definitive landslide susceptibility map for the study area was beyond the scope of our investigation. Instead, we performed pairwise comparative analyses in which we only changed, across the compared model assessments, the region of logistic regression training.

Code availability. - The software developed in this work to delineate the effective surveyed area, r.survey.py, is contained in the Supplement

- The software developed in Alvioli et al. (2016) to parametrically delineate slope units, r.slopeunits, is available at http://geomorphology.irpi.cnr.it/tools/slope-units (last access: 17 April 2017)

- The software developed in Rossi and Reichenbach (2016) for the statistical assessment of landslide susceptibility zonation, LAND-SE, is available at https://github.com/maurorossi/ LAND-SE (last access: 15 December 2016)

\section{The Supplement related to this article is available online at https://doi.org/10.5194/nhess-18-2455-2018- supplement.}

Author contributions. All the authors of the current research paper contributed actively in the presented investigation. TB carried put all the pertinent calculations as well as the production of the figures and redaction of the text that shows the results. MR has assisted in the statistical model development by means of the LAND-SE software and also contributed to the results discussion. IM performed the r.survey code and applied it to delimiting the ESA for this particular case study. In the same way, he actively took part in the different discussions concerning the results. MA developed the SU delimitation map and supervised the whole investigation, offering his point of view about the interpretation of the results as well as the redaction of the paper itself.

Competing interests. The authors declare that they have no conflict of interest.

Acknowledgements. This work has been funded by the Cultural Landscape and Heritage UNESCO Chair of the University of the Basque Country (UPV/EHU), and the article could not have been possible without the support of the IT1029-16 research group funded by the Basque government, whose head Iñaki Antigüedad has provided his direct collaboration. Authors are also grateful to Orbange Ormaetxea for her collaboration during the manuscript corrections. Part of this work was carried out by Txomin Bornaetxea during a scientific visit at CNR IRPI.

Edited by: Filippo Catani

Reviewed by: Marj Tonini and one anonymous referee

\section{References}

Alvioli, M., Marchesini, I., Reichenbach, P., Rossi, M., Ardizzone, F., Fiorucci, F., and Guzzetti, F.: Automatic delineation of geomorphological slope units with r.slopeunits v1.0 and their optimization for landslide susceptibility modeling, Geosci. Model Dev., 9, 3975-3991, https://doi.org/10.5194/gmd-9-3975-2016, 2016.

Alvioli, M., Melillo, M., Guzzetti, F., Rossi, M., Palazzi, E., von Hardenberg, J., Brunetti, M. T., and Peruccacci, S.: Implications of climate change on landslide hazard in Central Italy, Sci. Total Environ., 630, 1528-1543, https://doi.org/10.1016/j.scitotenv.2018.02.315, 2018a.

Alvioli, M., Mondini, A. C., Fiorucci, F., Cardinali, M., and Marchesini, I.: Topography-driven satellite imagery analysis for landslide mapping, Geomat. Nat. Haz. Risk, 9, 544-567, https://doi.org/10.1080/19475705.2018.1458050, 2018b.

Amorim, S. F.: Estudio comparativo de métodos para la evaluación de la susceptibilidad del terreno a la formacion de deslizamientos superficiales: Aplicación al Pirineo Oriental, $\mathrm{PhD}$ thesis, Universidad Politécnica de Catalunya, available at: http://futur.upc.edu/ 10953986 (last access: 15 July 2015), 2012.

Ayalew, L. and Yamagishi, H.: The application of GIS-based logistic regression for landslide susceptibility mapping in the KakudaYahiko Mountains, Central Japan, Geomorphology, 65, 15-31, https://doi.org/10.1016/j.geomorph.2004.06.010, 2005.

Ba, Q., Chen, Y., Deng, S., Yang, J., and Li, H.: A comparison of slope units and grid cells as mapping units for landslide susceptibility assessment, Earth Sci. Inform., 1-16, https://doi.org/10.1007/s12145-018-0335-9, 2018.

Blais-Stevens, A., Behnia, P., Kremer, M., Page, A., Kung, R., and Bonham-Carter, G.: Landslide susceptibility mapping of the Sea to Sky transportation corridor, British Columbia, Canada: comparison of two methods, B. Eng. Geol. Environ., 71, 447-466, https://doi.org/10.1007/s10064-012-0421-z, 2012.

Brabb, E. E.: Innovative approaches to landslide hazard and risk mapping, 4th International Symposium on Landslides, Toronto, 307-324, 1984.

Camilo, D. C., Lombardo, L., Mai, P. M., Dou, J., and Huser, R.: Handling high predictor dimensionality in slope-unit-based landslide susceptibility models through LASSO-penalized Generalized Linear Model, Environ. Model. Softw., 97, 145-156, https://doi.org/10.1016/j.envsoft.2017.08.003, 2017.

Carrara, A., Cardinali, M., Detti, R., Guzzetti, F., Pasqui, V., and Reichenbach, P.: GIS techniques and statistical models in evaluating landslide hazard, Earth Surf. Proc. Land., 16, 427-445, https://doi.org/10.1002/esp.3290160505, 1991.

Carrara, A., Cardinali, M., Guzzetti, F., and Reichenbach, P.: GIS technology in mapping landslide hazard, in: Geographical Information Systems in Assessing Natural Hazards, edited by: Carrara, A. and Guzzetti, F., Kluwer, Dordrecht, 135-176, https://doi.org/10.1007/978-94-015-8404-3_8, 1995.

Carrara, A., Crosta, G., and Frattini, P.: Comparing models of debris-flow susceptibility in the 
alpine environment, Geomorphology, 94, 353-378, https://doi.org/10.1016/j.geomorph.2006.10.033, 2008.

Casagli, N., Frodella, W., Morelli, S., Tofani, V., Ciampalini, A., Intrieri, E., Raspini, F., Rossi, G., Tanteri, L., and Lu, P.: Spaceborne, UAV and ground-based remote sensing techniques for landslide mapping, monitoring and early warning, Geoenvironmental Disasters, 4, 9 pp., https://doi.org/10.1186/s40677-0170073-1, 2017.

Cascini, L.: Applicability of landslide susceptibility and hazard zoning at different scales, Eng. Geol., 102, 164-177, https://doi.org/10.1016/j.enggeo.2008.03.016, 2008.

Catani, F., Farina, P., Moretti, S., Nico, G., and Strozzi, T.: On the application of SAR interferometry to geomorphological studies: estimation of landform attributes and mass movements, Geomorphology, 66, 119-131, https://doi.org/10.1016/j.geomorph.2004.08.012, 2005.

Cohen, J.: A coefficient of agreement for nominal scales, Educ. Psychol. Meas., 20, 37-46, https://doi.org/10.1177/001316446002000104, 1960.

Corominas, J. and Mavrouli, O. C.: Living with landslide risk in Europe: Assessment, effects of global change, and risk management strategies, Tech. rep., SafeLand, 7th Framework Programme Cooperation Theme 6 Environment (including climate change) SubActivity 6.1.3 Natural Hazards, 2011.

Corominas, J., Mateos, R. M., and Remondo, J.: Review of landslide occurrence in Spain and its relation to climate, Slope Safety Preparedness for Impact of Climate Change, 351 pp., 2017.

Costanzo, D., Chacón, J., Conoscenti, C., Irigaray, C., and Rotigliano, E.: Forward logistic regression for earth-flow landslide susceptibility assessment in the Platani river basin (southern Sicily, Italy), Landslides, 11, 639-653, https://doi.org/10.1007/s10346-013-0415-3, 2014.

Cruden, D. M. and Varnes, D. J.: Landslide types and processes, in: Landslides: Investigation and Mitigation. National Research Council, Transportation and Research Board Special Report 247, edited by: Turner, A. K. and Schuster R. L., National Academy Press, Washington, DC, 36-75, 1960.

Das, I., Sahoo, S., van Westen, C., Stein, A., and Hack, R.: Landslide susceptibility assessment using logistic regression and its comparison with a rock mass classification system, along a road section in the northern Himalayas (India), Geomorphology, 114, 627-637, https://doi.org/10.1016/j.geomorph.2009.09.023, 2010.

Davison, A. C. and Hinkley, D. V.: Bootstrap methods and their application, vol. 1, Cambridge university press, 1997.

Efron, B.: Bootstrap methods: another look at the jackknife, in: Breakthroughs in statistics, Springer, 569-593, 1992.

Ermini, L., Catani, F., and Casagli, N.: Artificial neural networks applied to landslide susceptibility assessment, Geomorphology, 66, 327-343, https://doi.org/10.1016/j.geomorph.2004.09.025, 2005.

EVE: Mapa Geológico del País Vasco Escala 1:100.000, Basque Energy Agency-Basque Gobernment, 2010.

Fawcett, T.: An introduction to ROC analysis, Pattern Recogn. Lett., 27, 861-874, https://doi.org/10.1016/j.patrec.2005.10.010, 2006.

Felicísimo, A. M., Cuartero, A., Remondo, J., and Quirós, E.: Mapping landslide susceptibility with logistic regression, multiple adaptive regression splines, classification and regression trees, and maximum entropy methods: a comparative study, Land- slides, 10, 175-189, https://doi.org/10.1007/s10346-012-0320-1, 2013.

Fiorucci, F., Cardinali, M., Carlà, R., Rossi, M., Mondini, A., Santurri, L., Ardizzone, F., and Guzzetti, F.: Seasonal landslide mapping and estimation of landslide mobilization rates using aerial and satellite images, Geomorphology, 129, 59-70, https://doi.org/10.1016/j.geomorph.2011.01.013, 2011.

Fiorucci, F., Giordan, D., Santangelo, M., Dutto, F., Rossi, M., and Guzzetti, F.: Criteria for the optimal selection of remote sensing optical images to map event landslides, Nat. Hazards Earth Syst. Sci., 18, 405-417, https://doi.org/10.5194/nhess-18-4052018, 2018.

González-Hidalgo, J. C., Brunetti, M., and de Luis, M.: A new tool for monthly precipitation analysis in Spain: MOPREDAS database (monthly precipitation trends December 1945-November 2005), Int. J. Climatol., 31, 715-731, https://doi.org/10.1002/joc.2115, 2011.

Gutiérrez, F., Soldati, M., Audemard, F., and Bălteanu, D.: Recent advances in landslide investigation: issues and perspectives, Geomorphology, 124, 95-101, https://doi.org/10.1016/j.geomorph.2010.10.020, 2010.

Guzzetti, F., Reichenbach, P., Cardinali, M., Galli, M., and Ardizzone, F.: Probabilistic landslide hazard assessment at the basin scale, Geomorphology, 72, 272-299, https://doi.org/10.1016/j.geomorph.2005.06.002, 2005.

Guzzetti, F., Reichenbach, P., Ardizzone, F., Cardinali, M., and Galli, M.: Estimating the quality of landslide susceptibility models, Geomorphology, 81, 166-184, https://doi.org/10.1016/j.geomorph.2006.04.007, 2006.

Guzzetti, F., Mondini, A. C., Cardinali, M., Fiorucci, F., Santangelo, M., and Chang, K. T.: Landslide inventory maps: New tools for an old problem, Earth-Sci. Rev., 112, 42-66, https://doi.org/10.1016/j.earscirev.2012.02.001, 2012.

Herrera, G., Fernández-Merodo, J., Mulas, J., Pastor, M., Luzi, G., and Monserrat, O.: A landslide forecasting model using ground based SAR data: The Portalet case study, Eng. Geol., 105, 220230, https://doi.org/10.1016/j.enggeo.2009.02.009, 2009.

Hosmer Jr., D. W., Lemeshow, S., and Sturdivant, R. X.: Applied logistic regression, vol. 398, John Wiley \& Sons, 2013.

IDE de Euskadi: Mapa geomorfológico de Euskadi, available at: www.geo.euskadi.eus (last access: 23 January 2017), 2014.

INGEMISA: Inventario y Análisis de las Áreas sometidas a Riesgo de Inestabilidades del Terreno de la C.A.P.V., Tech. rep., Eusko Jaurlaritza, 1995.

Lee, S. and Min, K.: Statistical analysis of landslide susceptibility at Yongin, Korea, Environ. Geol., 40, 1095-1113, https://doi.org/10.1007/s002540100310, 2001.

Liberatoscioli, E., van Westen, C. J., and Soldati, M.: Assessment of landslide susceptibility for civil protection purposes by means of GIS and statistical analysis: lessons from the Province of Modena, Italy, Revista de Geomorfologie, 19, 29-43, 2017.

Lombardo, L., Cama, M., Conoscenti, C., Märker, M., and Rotigliano, E.: Binary logistic regression versus stochastic gradient boosted decision trees in assessing landslide susceptibility for multiple-occurring landslide events: application to the 2009 storm event in Messina (Sicily, southern Italy), Nat. Hazards, 79, 1621-1648, 2015.

Malamud, B. D., Turcotte, D. L., Guzzetti, F., and Reichenbach, P.: Landslide inventories and their statistical properties, Earth Surf. 
Proc. Land., 29, 687-711, https://doi.org/10.1002/esp.1064, 2004.

Minelli, A., Marchesini, I., Taylor, F. E., De Rosa, P., Casagrande, L., and Cenci, M.: An open source GIS tool to quantify the visual impact of wind turbines and photovoltaic panels, Environ. Impact. Assess., 49, 70-78, https://doi.org/10.1016/j.eiar.2014.07.002, 2014.

Mondini, A. C.: Measures of Spatial Autocorrelation Changes in Multitemporal SAR Images for Event Landslides Detection, Remote Sensing, 9, 554, https://doi.org/10.3390/rs9060554, 2017.

Mücher, C. A., Klijn, J. A., Wascher, D. M., and Schaminée, J. H.: A new European Landscape Classification (LANMAP): A transparent, flexible and user-oriented methodology to distinguish landscapes, Ecol. Indic., 10, 87-103, https://doi.org/10.1016/j.ecolind.2009.03.018, 2010.

Murillo-García, F. G., Alcántara-Ayala, I., Ardizzone, F., Cardinali, M., Fiourucci, F., and Guzzetti, F.: Satellite stereoscopic pair images of very high resolution: a step forward for the development of landslide inventories, Landslides, 12, 277-291, https://doi.org/10.1007/s10346-014-0473-1, 2015.

Nefeslioglu, H., Gokceoglu, C., and Sonmez, H.: An assessment on the use of logistic regression and artificial neural networks with different sampling strategies for the preparation of landslide susceptibility maps, Eng. Geol., 97, 171-191, https://doi.org/10.1016/j.enggeo.2008.01.004, 2008.

Petley, D., Dunning, S., Rosser, N., and Hungr, O.: The analysis of global landslide risk through the creation of a database of worldwide landslide fatalities, Landslide risk management, Balkema, Amsterdam, 367-374, 2005.

Reichenbach, P., Rossi, M., Malamud, B., Mihir, M., and Guzzetti, F.: A review of statistically-based landslide susceptibility models, Earth-Sci. Rev., 180, 60-91, https://doi.org/10.1016/j.earscirev.2018.03.001, 2018.

Rodrigues, M., Montañés, C., and Fueyo, N.: A method for the assessment of the visual impact caused by the large-scale deployment of renewable-energy facilities, Environ. Impact Asses., 30, 240-246, https://doi.org/10.1016/j.eiar.2009.10.004, 2010.

Rosi, A., Tofani, V., Tanteri, L., Stefanelli, C. T., Agostini, A., Catani, F., and Casagli, N.: The new landslide inventory of Tuscany (Italy) updated with PS-InSAR: geomorphological features and landslide distribution, Landslides, 15, 5-19, 2018.

Rossi, M. and Reichenbach, P.: LAND-SE: a software for statistically based landslide susceptibility zonation, version 1.0, Geosci. Model Dev., 9, 3533-3543, https://doi.org/10.5194/gmd-9-35332016, 2016.

Rossi, M., Guzzetti, F., Reichenbach, P., Mondini, A. C., and Peruccacci, S.: Optimal landslide susceptibility zonation based on multiple forecasts, Geomorphology, 114, 129-142, https://doi.org/10.1016/j.geomorph.2009.06.020, 2010.

Santacana Quintas, N.: Análisis de la susceptibilidad del terreno a la formación de deslizamientos superficiales y grandes deslizamientos mediante el uso de sistemas de información geográfica, Aplicación a la cuenca alta del río Llobregat, $\mathrm{PhD}$ thesis, Universitat Politècnica de Catalunya, Barcelona, available at: https: //www.tdx.cat/handle/10803/6213 (last access: 15 July 2015), 2001.

Santangelo, M., Marchesini, I., Bucci, F., Cardinali, M., Fiorucci, F., and Guzzetti, F.: An approach to reduce mapping errors in the production of landslide inventory maps, Nat. Hazards
Earth Syst. Sci., 15, 2111-2126, https://doi.org/10.5194/nhess15-2111-2015, 2015.

Schicker, R. D.: Quantitative landslide susceptibility assessment of the Waikato region using GIS, PhD thesis, The University of Waikato, 2010.

Schlögel, R., Marchesini, I., Alvioli, M., Reichenbach, P., Rossi, M., and Malet, J. P.: Optimizing landslide susceptibility zonation: Effects of DEM spatial resolution and slope unit delineation on logistic regression models, Geomorphology, 301, 10 20, https://doi.org/10.1016/j.geomorph.2017.10.018, 2018.

Trigila, A., Iadanza, C., Esposito, C., and Scarascia-Mugnozza, G.: Comparison of Logistic Regression and Random Forests techniques for shallow landslide susceptibility assessment in Giampilieri (NE Sicily, Italy), Geomorphology, 249, 119-136, https://doi.org/10.1016/j.geomorph.2015.06.001, 2015.

Valagussa, A., Frattini, P., Crosta, G. B., Valbuzzi, E., and Gambini, S.: Regional landslide susceptibility analysis following the 2015 Nepal Earthquake, in: Workshop on World Landslide Forum, Springer, 1035-1042, 2017.

Van Den Eeckhaut, M., Vanwalleghem, T., Poesen, J., Govers, G., Verstraeten, G., and Vandekerckhove, L.: Prediction of landslide susceptibility using rare events logistic regression: a case-study in the Flemish Ardennes (Belgium), Geomorphology, 76, 392410, https://doi.org/10.1016/j.geomorph.2005.12.003, 2006.

Van Den Eeckhaut, M., Hervás, J., Jaedicke, C., Malet, J. P., Montanarella, L., and Nadim, F.: Statistical modelling of Europewide landslide susceptibility using limited landslide inventory data, Landslides, 9, 357-369, https://doi.org/10.1007/s10346011-0299-z, 2012.

Wang, F., Xu, P., Wang, C., Wang, N., and Jiang, N.: Application of a GIS-Based Slope Unit Method for Landslide Susceptibility Mapping along the Longzi River, Southeastern Tibetan Plateau, China, ISPRS Int. J. Geo-Inf., 6, 172 pp., https://doi.org/10.3390/ijgi6060172, 2017.

Wang, Y. T., Seijmonsbergen, A. C., Bouten, W., and Chen, Q. T.: Using statistical learning algorithms in regional landslide susceptibility zonation with limited landslide field data, J. Mt. Sci., 12, 268-288, https://doi.org/10.1007/s11629-014-3134-x, 2015.

Yesilnacar, E. and Topal, T.: Landslide susceptibility mapping: a comparison of logistic regression and neural networks methods in a medium scale study, Hendek region (Turkey), Eng. Geol., 79, 251-266, https://doi.org/10.1016/j.enggeo.2005.02.002, 2005.

Yilmaz, I.: Landslide susceptibility mapping using frequency ratio, logistic regression, artificial neural networks and their comparison: a case study from Kat landslides (Tokat-Turkey), Comput. Geosci., 35, 1125-1138, https://doi.org/10.1016/j.cageo.2008.08.007, 2009.

Zêzere, J., Pereira, S., Melo, R., Oliveira, S., and Garcia, R.: Mapping landslide susceptibility using datadriven methods, Sci. Total Environ., 589, 250-267, https://doi.org/10.1016/j.scitotenv.2017.02.188, 2017.

Zhou, C., Yin, K., Cao, Y., Ahmed, B., Li, Y., Catani, F., and Pourghasemi, H. R.: Landslide susceptibility modeling applying machine learning methods: A case study from Longju in the Three Gorges Reservoir area, China, Comput. Geosci., 112, 23 37, https://doi.org/10.1016/j.cageo.2017.11.019, 2018. 